\title{
Renal Biopsy in Children-Effect on Treatment Decisions: A Single-Center Experience: Authors' Reply
}

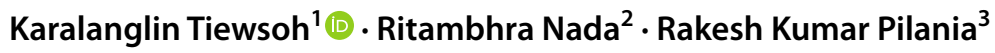

Received: 2 October 2021 / Accepted: 27 October 2021/Published online: 19 January 2022

(c) Dr. K C Chaudhuri Foundation 2021

To the Editor: We thank Suprita Kalra for bringing out certain significant points related to our study, that would be important for the clinician who decides whether a child requires a renal biopsy [1]. In our study, we found that renal biopsy made significant treatment changes in patients having nephrotic range proteinuria with atypical features and in those with acute kidney injury (AKI) stage 3 [2]. However, we wish to clarify, that renal biopsy was done in children according to the recommended guidelines and there were no specific clinical or laboratory parameters that prompted us to do any early renal biopsy [3, 4].

It is important to note that, there were certain diagnoses where management was based mainly on the histopathological diagnosis. Renal biopsy of a child with steroid-resistant nephrotic syndrome revealed amyloidosis with underlying etiology of autoinflammatory disease, cryopyrin-associated periodic syndrome (CAPS) [5]. Besides, another child with AKI had evidence of renal mucormycosis on biopsy. While these diagnoses are rare in children, yet we are assured that if we follow the guidelines for performing a renal biopsy, these conditions too will be detected. Similarly, in patients with lupus nephritis, 2 patients showed class V (membranous) lupus nephritis and treatment was accordingly modified.

Further, while it is prudent to have renal biopsy specimens examined by light microscopy, immunofluorescence, and electron microscopy (EM), the latter is usually not available everywhere [6]. EM proved essential in podocytopathy, C3 glomerulopathy, and Alport syndrome, and helpful in

Karalanglin Tiewsoh

ktiewsoh@rediffmail.com

1 Pediatric Nephrology Unit, Department of Pediatrics, Post Graduate Institute of Medical Education and Research, Chandigarh 160012, India

2 Department of Histopathology, Post Graduate Institute of Medical Education and Research, Chandigarh, India

3 Department of Pediatrics, Post Graduate Institute of Medical Education and Research, Chandigarh, India lupus nephritis, membranous nephropathy, and diffuse proliferative glomerulonephritis though it was not needed in thrombotic microangiopathy. In those with collapsing glomerulopathy, EM helped us to rule out a viral etiology, while it ruled out toxin injury in acute tubular necrosis.

\section{Declarations}

Conflict of Interest None.

\section{References}

1. Kalra S. Renal biopsy in children —effect on treatment decisions: a single-center experience: correspondence. Indian J Pediatr. 2021. https://doi.org/10.1007/s12098-021-04041-8.

2. Pilania RK, Venkatesh GV, Nada R, et al. Renal biopsy in childreneffect on treatment decisions: a single-center experience. Indian J Pediatr. 2021;88:1036-9.

3. Indian Pediatric Nephrology Group, Indian Academy of Pediatrics, Bagga A, et al. Management of steroid sensitive nephrotic syndrome: revised guidelines. Indian Pediatr. 2008;45:203-14.

4. Disease K. Improving Global Outcomes (KDIGO) Glomerulonephritis Work Group. KDIGO clinical practice guideline for glomerulonephritis. Kidney Int Suppl. 2012;2:139-274.

5. Pandiarajan V, Gupta A, Rowczenio D, et al. Nephrotic syndrome as a presenting feature in a child with NLRP3 mutation. J Clin Rheumatol. 2021;27:e217-9.

6. Rovin BH, Adler SG, Barratt J, et al. Executive summary of the KDIGO 2021 Guideline for the Management of Glomerular Diseases. Kidney Int. 2021;100:753-79.

Publisher's Note Springer Nature remains neutral with regard to jurisdictional claims in published maps and institutional affiliations. 